\title{
KURIKULUM PGRA BERBASIS KECERDASAN SPIRITUAL
}

\author{
Kisbiyanto
}

Dosen STAIN Kudus

\begin{abstract}
Childhood education is specific education because of its early education. C Childhood education is also a beginning to form Islamic personality. This specific education needs teachers who have competences, especially spiritual quotion. This study is a research with qualitative approach, focused on how the curriculum of PGRA. The main data collecting is study of documents, with description and analysis. The result of this study is the curriculum of PGRA in STAIN Kudus consists of spiritual quotion education for teacher training.
\end{abstract}

Keywords: Teacher Training, Spiritual Quotion

\section{A. Pendahuluan}

Pendidikan Islam mempunyai ciri khusus dibanding pendidikan pada umumnya, yaitu pada aspek landasan dan tujuan yang hendak dicapainya. Pendidikan Islam menyandarkan landasaran pemikiran dan konsepkonsepnya pada dasar agama Islam, yaitu al-Quran dan hadits. Tujuan pendidikan Islam untuk mendidik orang muslim menjadi manusia yang sempurna lahir dan batin, bahagia di dunia dan akhiratnya. Dengan kata lain, pendidikan merupakan media untuk menanamkan ilmu pengetahuan dan nilai-nilai spiritual keagamaan bagi pemeluk agama Islam.

Pendidikan Islam merupakan pendidikan yang berbasis pada spiritual agama Islam. Itulah ciri utama pendidikan Islam dengan pendidikan lainnya. Spiritual Islam sebagai basis nilai-nilai dalam pendidikan Islam menjadi semakin penting untuk mendapat pengkajian lebih mendalam terutama terkait dengan tindak pendidikan bagi tenaga pendidik yang akan menjadi guru bagi murid-muridnya. Spiritual agama juga terkait dengan pokokpokok materi pembelajaran yang harus dipahami dan kemudian diamalkan 
oleh para pendidik. Karena itu, sistem pembelajaran dengan kurikulum dalam pembelajaran klasikal harus dengan jelas mencanangkan materi ajar yang berkonten spiritual.

Pendidikan spiritual Islam juga harus diajarkan di semua jenis program studi ataupun jurusan, baik yang bidang pendidikan agama Islam misalnya pendidikan al-quran dan hadits, pendidikan akidah dan akhlak, pendidikan fiqih, pendidikan sejarah dan kebudayaan Islam, maupun pendidikan bahasa misalnya bahasa Arab, bahasa Inggris, bahasa Indonesia, dan juga pendidikan matematika, pendidikan sains, pendidikan fisika, pendidikan biologi, pendidikan kimia, dan termasuk pendidikan spesifik seperti pendidikan guru madrasah ibtidayah, maupun pendidikan guru anak usia dini. Secara manajerial kurikulum dasar dibagi menjadi tiga rumpun, yaitu kuikulum untuk materi dasar keilmuan, materi dasar keislaman, dan materi dasar setiap program studi. Materi dasar keislaman itu menjadi wadah bagi pendidikan spiritual keislaman, diajarkan di semua bidang peminatan.

Tujuan pendidikan spiritual Islam hanya satu, yaitu menjadikan para cerdik pandai dalam berbagai keilmuwan tetap harus dilandasi oleh nilainilai spiritual keislaman. Sarjana pendidikan dari berbagai disiplin ilmu dan pengetahuan dituntut untuk menguasai dengan baik dasar-dasar spiritualitas agama Islam. Tak terkecuali, pendidikan Islam yang diselenggarakan pada Program Studi Pendidikan Guru Raudlatul Athfal (PGRA) yang berdiri sejak tahun 2013 meneguhkan diri sebagai lembaga pendidikan tenaga kependidikan (LPTK) yang fokus pada penyiapan tenaga ahli dan terampil sebagai guru pendidikan anak usia dini, dengan kekhususan sebagai pendidik yang mempunyai berbagai keterampilan khusus sebagaimana tertuang dalam struktur kurikulumnya juga memperhatikan potensi dan kemampuan STAIN Kudus dan kearifan lokal Kudus, misalnya spesifikasi yang dimiliki oleh tenaga pendidik, sosial budaya pantura Jawa Tengah khususnya Kudus sebagai kota santri.

Undang Undang Republik Indonesia Nomor 20 Tahun 2003 tentang Sistem Pendidikan Nasional menjadi dasar utama pendidikan sebagaimana dinyatakan bahwa pendidikan adalah usaha sadar dan terencana untuk mewujudkan suasana belajar dan proses pembelajaran agar peserta didik secara aktif mengembangkan potensi dirinya untuk memiliki kekuatan spiritual keagamaan, pengendalian diri, kepribadian, kecerdasan, akhlak mulia, serta keterampilan yang diperlukan dirinya, masyarakat, bangsa dan negara. Salah satu kata kunci dari pendidikan bagi bangsa Indonesia adalah agar peserta didik memiliki kekuatan spiritual keagamaan. Undang 
Undang Republik Indonesia Nomor 14 Tahun 2005 tentang Guru dan Dosen yang mengamanatkan bahwa guru sebagai pendidik harus berkualifikasi sarjana atau diploma empat atau yang sederajat. Undang Undang Republik Indonesia Nomor 12 Tahun 2012 tentang Pendidikan Tinggi yang menjadi pijakan untuk penyelenggaraan pendidikan tinggi membekali yang tentunya merujuk kepada penjaminan mutu akademik.

Studi ini bersifat deskriptif, yaitu salah satu bentuk penelitian kualitatif sebagaimana disebutkan oleh McMillan (2001:29) yaitu penelitian dengan pendekatan kualitatif, dengan concept analysis. Pendekatan kualitatif ini untuk mengungkapkan konsep-konsep yang sebagaimana dirumuskan dalam dokumen akademik. Data-data spesifik dicari maknanya untuk membuat simpulan yang berupa makna-makna yang diperoleh dari datadata tersebut. Studi ini dimaksudkan untuk menjelaskan tentang konten pendidikan kecerdasan spiritual bagi calon pendidik. Sumber utama data adalah dokumentasi dan arsip-arsip yang relevan, yaitu naskah akademik yang merupakan naskah pengembangan kurikulum dan rumpun mata kuliah pada program studi PGRA. Agar studi ini memperoleh kesesuaian antara persoalan yang difokuskan dengan setting penelitian, sebagaimana dianjurkan oleh Moleong (1994:19), maka dilakukan penjajakan dan penilaian data-data. Demikian juga pengambilan data melalui dokumen dilakukan untuk mendapatkan informasi dari sumber yang berupa arsip dan naskah akademik yang relevan. Selanjutnya, data-data dianalisis dengan pemaknaan konten dan relevansinya, yaitu untuk mendapat simpulan atas konsep pengembangan kurikulum yang memuat pendidikan kecerdasan spiritual bagi calon pendidik.

\section{B. Pembahasan}

Pendidik di tingkat taman kanak-kanak merupakan peletak dasardasar kepribadian peserta didik. Kepribadian islami tidak terlepas dari kecerdasan spiritual yang harus dimiliki oleh pendidik sebelum mereka mengajar bagi peserta didiknya. Kecerdasan spiritual juga menjadi ciri yang khusus bagi pendidikan di bawah naungan pendidikan Islam. Pendidik yang berkepribadian islami selalu mengutamakan kekuatan spiritual bagi dirinya dan pendidikan spiritual bagi peserta didiknya.

Kurikulum program studi PGRA bertujuan untuk terwujudnya struktur kurikulum mengacu kerangka kualifikasi nasional Indonesia (KKNI) dan standar nasional pendidikan tinggi (SNPT), untuk menjadikan sarjana PGRA 132 yang responsif terhadap perkembangan dan tantangan global (Naskah 
Akademik 2016), dengan rumusan visi program studi PGRA adalah unggul dalam bidang pendidikan anakusia dini berwawasan Islam transformatif, dengan misi (1)menyelenggarakan pendidikan dan pembelajaran untuk menghasilkan tenaga pendidik dan pengelola bidang pendidikan Islam anak usia dini yang profesional, (2)menyelenggarakan kajian dan penelitian untuk pengembangan keilmuan dalam bidang pendidikan Islam anak usia dini, (3)melaksanakan pengabdian kepada masyarakat dalam bidang pendidikan Islam anak usia dini, (4)menjalin kerjasama dengan berbagai pihak untuk pengembangan penyelenggaraan pendidikan Islam usia dini. Kualifikasi yang harus dicapai oleh peserta didik pada program studi PGRA, sebagaimana dimaksud, yaitu terbagi dalam empat deskripsi generic yang bersifat umum dan masing-masing dideskripsikan secara khusus (Naskah Akademik 2016), sebagai berikut:

\begin{tabular}{|c|c|c|}
\hline No & Deskripsi Generik & Deskripsi Spesifik \\
\hline 1. & $\begin{array}{l}\text { Mampu memahami } \\
\text { dan menerapkan } \\
\text { Ipteks dalam bidang } \\
\text { keahlian Pendidikan } \\
\text { Islam Anak Usia Dini } \\
\text { dalam penyelesaian } \\
\text { masalah dan mampu } \\
\text { beradaptasi terhadap } \\
\text { situasi yang dihadapi }\end{array}$ & $\begin{array}{l}\text { 1. Mampu memanfaatkan teori-teori } \\
\text { kependidikan dan pembelajaran } \\
\text { AUD, psikologi, psikologi pendidikan, } \\
\text { psikologi perkembangan AUD, } \\
\text { metodologi penelitian pendidikan AUD } \\
\text { 2. Mampu menguasai bidang kajian } \\
\text { pendidikan anak usia dini dalam } \\
\text { perkembangan ilmupengetahuan } \\
\text { berbasis teknologi informasi } \\
\text { 3. Mampu berkomunikasi dalam } \\
\text { menyelesaikan masalah pembelajaran } \\
\text { didang pendidikan anak usia dini } \\
\text { 4. Memiliki beradaptasi dalam berbagai } \\
\text { situasi terkait dengan dinamika sosial- } \\
\text { budaya, ekonomi dan pilitik serta } \\
\text { tantangan global dalam pelaksanaaan } \\
\text { tugas pembelajaran pendidikan anak } \\
\text { usia dini }\end{array}$ \\
\hline 2. & $\begin{array}{l}\text { Menguasai konsep } \\
\text { teoretis bidang } \\
\text { pengetahuan tertentu } \\
\text { secara umum dan } \\
\text { konsep teoretis bagian } \\
\text { bidang pengetahuan } \\
\text { tersebut secara }\end{array}$ & $\begin{array}{l}\text { 1. Mampu memahami metodologi dalam } \\
\text { menerapkan teori pembelajaran, } \\
\text { psikologi dan evaluasi pembelajaran } \\
\text { pada PAUD } \\
\text { 2. Mampu mengkonseptulisasikan } \\
\text { dalam memaknai teori pembelajaran, } \\
\text { psikologi dan evaluasi pada PAUD }\end{array}$ \\
\hline
\end{tabular}




\begin{tabular}{|c|c|c|}
\hline & $\begin{array}{l}\text { mendalam, } \\
\text { serta mampu } \\
\text { memformulasikan } \\
\text { penyelesaian secara } \\
\text { procedural }\end{array}$ & $\begin{array}{l}\text { 3. Mampu menguasai metodologi } \\
\text { dalam mengaplikasikan teori } \\
\text { psikologi pendidikan dan psikologi } \\
\text { perkembangan pada AUD } \\
\text { 4. Mampu mengkonseptualisasikan dalam } \\
\text { memaknai teori psikologi pendidikan } \\
\text { dan psikologi perkembangan pada AUD }\end{array}$ \\
\hline 3. & $\begin{array}{l}\text { Mampu mengambil } \\
\text { keputusan strategis } \\
\text { berdasarkan analisis } \\
\text { informasi dan data } \\
\text { serta memberikan } \\
\text { petunjuk dalam } \\
\text { memilih berbagai } \\
\text { alternatif solusi }\end{array}$ & $\begin{array}{l}\text { 1. Mampu mendesain rencana, } \\
\text { implementasi, dan evaluasi } \\
\text { pembelajaran pada Pendidikan AUD } \\
\text { 2. Berkomitmen, loyal dan mencintai } \\
\text { profesi sebagai pendidik di PAUD }\end{array}$ \\
\hline 4. & $\begin{array}{l}\text { Bertanggung jawab } \\
\text { atas pekerjaan sendiri } \\
\text { dan dapat diberi } \\
\text { tanggung jawab atas } \\
\text { pencapaian hasil kerja } \\
\text { organisasi }\end{array}$ & $\begin{array}{l}\text { 1. Mampu berinisiasi dengan teori } \\
\text { pendidikan dan pembelajaran pada } \\
\text { pendidikan AUD } \\
\text { 2. Mampu berkreasi dan berinovasi dalam } \\
\text { mengaplikasikan teori pendidikan dan } \\
\text { pembelajaran pada AUD } \\
\text { 3. Bertanggung jawab secara keilmuan } \\
\text { dan keguruan dalam bidang pendidikan } \\
\text { AUD }\end{array}$ \\
\hline
\end{tabular}

Rumusan Capaian Pembelajaran Program Studi PGRA meliputi lima bidang capaian yang menjadi acuan, yaitu sikap dan tata nilai, pengetahuan umum, pengetahuan khusus, keterampilan umum, dan keterampilan khusus. Kelima bidang tersebut sebenarnya menekankan pada aspek landasan nilai, pengetahuan, dan keterampilan yang menjadi bidang yang harus dicapai oleh peserta didik yaitu para calon guru yang menempuh program pendidikan kesarjaaan bidang pendidikan anak usia dini selama kurang lebih empat tahun atau delapan semester. Kelima bidang dan deskripsi capaian pembelajaran sebagaimana tabel berikut ini : 


\begin{tabular}{|c|c|c|}
\hline NO & $\begin{array}{l}\text { BIDANG } \\
\text { CAPAIAN }\end{array}$ & CAPAIAN PEMBELAJARAN \\
\hline 1 & $\begin{array}{l}\text { Sikap dan } \\
\text { Tata Nilai }\end{array}$ & $\begin{array}{l}\text { 1. Mengedapankan nilai-nilai ke-Islaman yang } \\
\text { mencakup ketakwaan terhadap Allah SWT, } \\
\text { penghargaan terhadap nilai-nilai kemanusiaan, } \\
\text { internalisasi nilai dan norma } \\
\text { 2. Mengedepankan nilai-nilai ke-Indonesiaan } \\
\text { dan kemasyarakatan, meliputi, penghargaan } \\
\text { terhadap keanekaragaman, nasionalisme dan } \\
\text { tanggungjawab bernegara, dan berbangsa, } \\
\text { berdasarkan Pancasila } \\
\text { 3. Mengedepankan nilai-nilai etika akademik, yang } \\
\text { meliputi kejujuran dan kebebasan akademik dan } \\
\text { otonomi akademik } \\
\text { 4. Bertanggung jawab sepenuhnya terhadap nilai- } \\
\text { nilai akademik yang diembannya sebagai calon } \\
\text { guru PAUD }\end{array}$ \\
\hline 2 & $\begin{array}{l}\text { Pengetahuan } \\
\text { Umum }\end{array}$ & $\begin{array}{l}\text { 1. Mampu menguasai penguasaan pengetahuan } \\
\text { terkait dengan pengelolaan pembelajaran } \\
\text { yang mendidik, kreatif, inovatif, produktif dan } \\
\text { adaptif yang dicerminkan dengan kemampuan } \\
\text { memahami landasan pendidikan, perkembangan } \\
\text { peserta didik, pengembangan kurikulum, } \\
\text { landasan pembelajaran, pengembangan } \\
\text { perangkat pembelajaran, penilaian } \\
\text { pembelajaran, penguasaan dan pemanfaatan } \\
\text { teknologi informasi dan komunasi dalam } \\
\text { pembelajaran, kemampuan stimulasi peserta } \\
\text { didik dalam pengembangan potensi diri dan } \\
\text { mengaktualisasikannya secara tepat } \\
\text { 2. Mampu menguasai pengetahuan bidang keilmuan } \\
\text { secara luas dan mendalam berkaitan dengan } \\
\text { konsep, filosofi, metode disiplin keilmuan (body } \\
\text { of knowledge) pendidikan PAUD dan relevan } \\
\text { dengan tuntutan standar isi satuan pendidikan } \\
\text { dalam rangka mewujudkan }\end{array}$ \\
\hline
\end{tabular}




\begin{tabular}{|l|l|l|}
\hline & & $\begin{array}{l}\text { pembelajaran yang yang mendidik, kreatif, } \\
\text { inovatif, produktif dan adaptif } \\
\text { 3. }\end{array}$ \\
\hline Mampu menghafal Al-quran minimal juz 30 \\
\hline
\end{tabular}




\begin{tabular}{|l|l|l|}
\hline 5. & $\begin{array}{l}\text { Mampu mengambil keputusan secara tepat, } \\
\text { dalam konteks penjelasan masalah di bidang } \\
\text { keahliannya berdasarkan hasil analisis informasi } \\
\text { dan data }\end{array}$ \\
6. $\begin{array}{l}\text { Mampu memelihara dan mengembangkan } \\
\text { jaringan kerja dengan pembimbing, kolega } \\
\text { dan sejawat baik di dalam maupun di luar } \\
\text { lembaganya } \\
\text { 7. }\end{array}$ & $\begin{array}{l}\text { Mampu bertanggungjawab atas pencapaian } \\
\text { hasil kerja kelompok melakukan supervisi dan } \\
\text { evaluasi terhadap penyelesaian pekerjaan yang } \\
\text { ditugaskan kepada pekerja yang berada di bawah } \\
\text { tanggungjawabnya }\end{array}$ \\
8. $\begin{array}{l}\text { Mampu melakukan proses evaluasi diri } \\
\text { terhadap kelompok kerja yang berada di bawah } \\
\text { tanggungjawabnya dan mampu mengelola } \\
\text { pembelajaran secara mandiri }\end{array}$ \\
9. $\begin{array}{l}\text { Mampu mendokumentasikan, menyimpan, } \\
\text { mengamanahkan, dan menemukan kembali data } \\
\text { untuk menjamin kesahihan mencegah plagiasi }\end{array}$ \\
\hline Khusus
\end{tabular}




\begin{tabular}{|l|l|}
\hline & $\begin{array}{l}\text { 9. } \text { Terampil merancang manajemen pendidikan } \\
\text { yang kondusif pada pendidikan AUD } \\
\text { 10. Terampil menerapkan teori kreativitas dan } \\
\text { keberbakatan pada pendidikan AUD } \\
\text { 11. Terampil menerapkan teori pengembangan fisik- } \\
\text { motorik, kognitif-bahasa, sosio-emosi dan nilai } \\
\text { moral dan agama peserta didik pada manajemen } \\
\text { pembelajaran pada pendidikan AUD } \\
\text { 12. Terampil dalam pengembangan seni musik, seni } \\
\text { suara, seni tari dan seni drama dalam pendidikan } \\
\text { AUD }\end{array}$ \\
\hline
\end{tabular}

Kelima bidang capaian di atas itu, disusun sedemikian rupa mulai dari sistem nilai yang melandasi hingga sistem pengetahuan dan sistem keterampilan yang sehingga kriteria ini akan menentukan kemampuan lulusan dari program studi PGRA yang fokus pada pendidikan anak usia dini. Hal ini senada dengan rumusan Newman (1994 : 74-75) yang merumuskan pendidikan bagi guru harus fokus pada aspek general knowledge, teaching field, dan professional education. Dengan sistem nilai, pengetahuan, dan keterampilan ini, lulusan sebagai sarjana pendidikan mempunyai profil sebagai guru yang profesional. Profil lulusan dan capaian pembelajaran yang dimaksud sebagimana berikut ini :

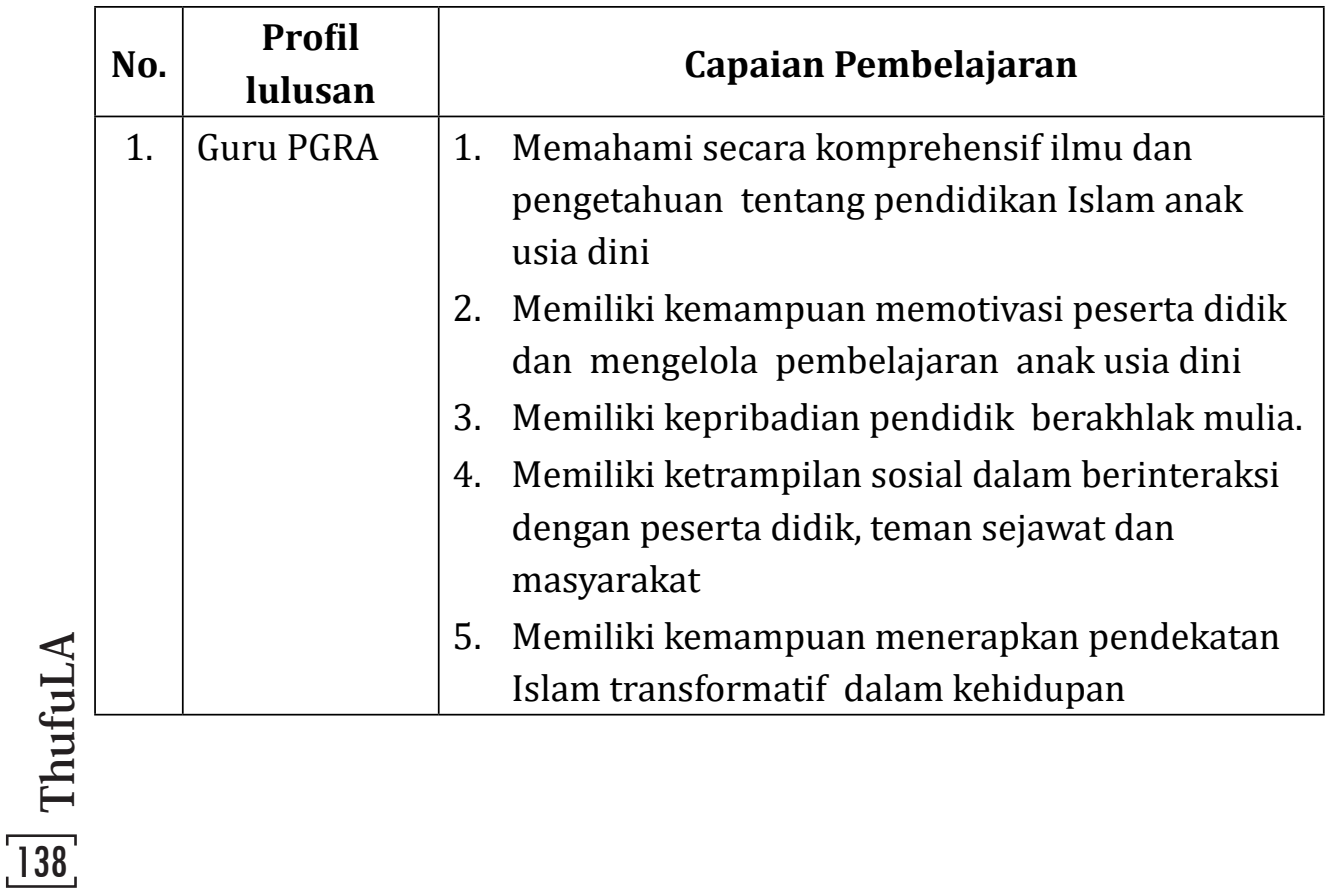




\begin{tabular}{|l|l|ll|}
\hline 2. & Pengelola & 1. & $\begin{array}{l}\text { Memahami teori dan konsep managemen } \\
\text { kependidikan untuk mengelola lembaga } \\
\text { PGRA }\end{array}$ \\
$\begin{array}{l}\text { 2. } \\
\text { Pendidikan Islam anak usia dini } \\
\text { administrasi kependidikan Islam anak usia dini }\end{array}$ \\
\hline
\end{tabular}

Ada tiga rumpun pengelompokan mata kuliah yaitu rumpun mata kuliah tingkat perguruan tinggi, rumpun mata kuliah tingkat jurusan, dan rumpun mata kuliah tingkat program studi. Setiap rumpun mata kuliah itu mempunyai konten pada materi khusus keagamaan, yang berarti bahwa pendidikan kecerdasan spiritual keagamaan menjadi landasan utama struktur kurikulum bagi calon pendidik. Peserta didik pada program studi PGRA disiapkan untuk menjadi guru pada lembaga-lembaga pendidikan bagi anak usia dini, seperti di raudlatul athfal, taman kanak-kanak, dan kelompok bermain. Ketiga rumpun mata kuliah beserta konten pendidikan keagamaan Islam, sebagaimana berikut ini :

\section{Konten Kecerdasan Spiritual}

Mata Kuliah Rumpun Perguruan Tinggi

\begin{tabular}{|c|c|c|c|}
\hline No & $\begin{array}{l}\text { Capaian } \\
\text { Pembelajaran }\end{array}$ & Bahan Kajian & Mata Kuliah \\
\hline 1 & $\begin{array}{l}\text { Mampu melaksanakan } \\
\text { sikap dan kepribadian } \\
\text { yang baik dalam } \\
\text { kehidupan berbangsa } \\
\text { dan bernegara sesuai } \\
\text { dengan pendekatan } \\
\text { Islam transformatif }\end{array}$ & $\begin{array}{l}\text { Landasan } \\
\text { Keagamaan dan } \\
\text { Kebangsaan }\end{array}$ & $\begin{array}{l}\text { 1. Ilmu Tauhid } \\
\text { 2. Tasawuf } \\
\text { 3. Pendidikan } \\
\text { Pancasila dan } \\
\text { Kewarganegaraan } \\
\text { (PPKn) }\end{array}$ \\
\hline 2 & $\begin{array}{l}\text { Mampu memahami } \\
\text { metodologi ilmu-ilmu } \\
\text { keislaman }\end{array}$ & $\begin{array}{l}\text { Metodologi } \\
\text { kajian } \\
\text { keislaman }\end{array}$ & $\begin{array}{l}\text { 4. Metodologi Studi } \\
\text { Islam } \\
\text { 5. Ulumul Qur'an } \\
\text { 6. Ulumul Hadits } \\
\text { 7. Ushul Fiqih }\end{array}$ \\
\hline 3 & $\begin{array}{l}\text { Mampu memahami } \\
\text { sumber-sumber dasar } \\
\text { keislaman }\end{array}$ & $\begin{array}{l}\text { Dasar kajian } \\
\text { keislaman }\end{array}$ & $\begin{array}{ll}\text { 8. } & \text { Tafsir } \\
\text { 9. } & \text { Hadits }\end{array}$ \\
\hline
\end{tabular}




\begin{tabular}{|l|l|l|l|}
\hline 4 & $\begin{array}{l}\text { Mampu memahami } \\
\text { kebudayaan dan } \\
\text { peradaban Islam }\end{array}$ & $\begin{array}{l}\text { Peradaban } \\
\text { Islam }\end{array}$ & $\begin{array}{l}\text { 10. Fiqih } \\
\text { 11. Sejarah Peradaban } \\
\text { Islam }\end{array}$ \\
\hline 5 & $\begin{array}{l}\text { Mampu mengamalkan } \\
\text { ajaran Islam } \\
\text { dan berperan } \\
\text { dalam kehidupan } \\
\text { bermasyarakat }\end{array}$ & $\begin{array}{l}\text { Ketrampilan } \\
\text { beragama dan } \\
\text { bermasyarakat }\end{array}$ & $\begin{array}{l}\text { 12. Praktik Ibadah dan } \\
\text { Tahfidz } \\
\text { 13. KKN }\end{array}$ \\
\hline
\end{tabular}

Konten Kecerdasan Spiritual

Mata Kuliah Rumpun Jurusan Tarbiyah

\begin{tabular}{|c|c|c|c|}
\hline No & $\begin{array}{l}\text { Capaian } \\
\text { Pembelajaran }\end{array}$ & Bahan Kajian & Mata Kuliah \\
\hline 1 & $\begin{array}{l}\text { Memahami konsep } \\
\text { pendidikan dan } \\
\text { pendidikan Islam }\end{array}$ & $\begin{array}{l}\text { Landasan } \\
\text { pendidikan } \\
\text { Islam }\end{array}$ & $\begin{array}{l}\text { 1. Ilmu Pendidikan } \\
\text { 2. Ilmu Pendidikan } \\
\text { Islam } \\
\text { 3. Tafsir Tarbawi } \\
\text { 4. } \\
\text { Hadist Tarbawi }\end{array}$ \\
\hline 2 & $\begin{array}{l}\text { Menguasai landasan } \\
\text { filosofis pendidikan } \\
\text { Islam dengan berbagai } \\
\text { unsurnya }\end{array}$ & $\begin{array}{l}\text { Dasar } \\
\text { pemikiran } \\
\text { pendidikan } \\
\text { Islam }\end{array}$ & $\begin{array}{l}\text { 5. Filsafat Pendidikan } \\
\text { Islam }\end{array}$ \\
\hline 3 & $\begin{array}{l}\text { Memahami dan } \\
\text { menerapkan teori- } \\
\text { teori bimbingan dan } \\
\text { konseling untuk } \\
\text { menyelesaikan } \\
\text { masalah dalam bidang } \\
\text { pendidikan }\end{array}$ & $\begin{array}{l}\text { Bimbingan dan } \\
\text { konseling }\end{array}$ & $\begin{array}{l}\text { 6. Bimbingan dan } \\
\text { Konseling }\end{array}$ \\
\hline
\end{tabular}


Konten Kecerdasan Spiritual

Mata Kuliah Rumpun Program Studi PGRA

\begin{tabular}{|c|c|c|c|}
\hline No & $\begin{array}{c}\text { Capaian } \\
\text { Pembelajaran }\end{array}$ & Bahan Kajian & Mata Kuliah \\
\hline 1 & $\begin{array}{l}\text { Mampu menerapkan } \\
\text { pembelajaran al- } \\
\text { Qur'an Hadits untuk } \\
\text { anak usia dini }\end{array}$ & Qur'an Hadist & $\begin{array}{l}\text { 1. Pembelajaran al- } \\
\text { Quran Hadits AUD }\end{array}$ \\
\hline 2 & $\begin{array}{l}\text { Mampu memahami } \\
\text { tahap-tahap } \\
\text { pertumbuhan dan } \\
\text { perkembangan } \\
\text { berdasarkan laporan } \\
\text { data perkembangan } \\
\text { anak }\end{array}$ & $\begin{array}{l}\text { Pengembangan } \\
\text { perilaku }\end{array}$ & $\begin{array}{l}\text { 2. Psikologi } \\
\text { Perkembangan } \\
\text { 3. Pengembangan } \\
\text { Kemampuan Fisik } \\
\text { Motorik AUD } \\
\text { 4. Pengembangan } \\
\text { kemampuan Kognitif } \\
\text { dan Bahasa AUD } \\
\text { 5. Pengembangan } \\
\text { Kemampuan Sosial } \\
\text { Emosi AUD } \\
\text { 6. Pengembangan } \\
\text { Kemampuan Nilai } \\
\text { Moral dan Agama } \\
\text { AUD } \\
\text { 7. Assesmen } \\
\text { Perkembangan Psiko } \\
\text { Fisik AUD }\end{array}$ \\
\hline 3 & $\begin{array}{l}\text { Memahami, } \\
\text { menganalisis } \\
\text { dan menentukan } \\
\text { problem solving pada } \\
\text { masalah-masalah } \\
\text { perkembangan anak }\end{array}$ & $\begin{array}{l}\text { Pendidikan } \\
\text { inklusi }\end{array}$ & $\begin{array}{l}\text { 8. Kesehatan Mental } \\
\text { 9. Pendidikan Anak } \\
\text { Berkebutuhan } \\
\text { Khusus (ABK) }\end{array}$ \\
\hline
\end{tabular}

Materi dasar keagamaan disatukan dengan materi dasar-dasar kebangsaan. Nilai spiritualitas agama tidak terpisahkan dengan konsep berbangsa dan bernegara. Konsensus nasional bangsa Indonesia memang dengan tegas menyatakan bahwa bangsa dan negara Indonesia adalah negara bangsa sekaligus bangsa yang berketuhanan. Negara tidak harus 141 
berbentuk teokrasi yang menjelma menjadi negara agama, tetapi negara yang memberikan jaminan kepada warga negaranya untuk semaksimal mungkin menjalankan syariat agama. Ali (2010 1:2) menyatakan bahwa secara garis besar masyarakat Indonesia sangat mendukung negara dengan dasar Pancasila dari pada negara Islam atau sebutan lain yang menunjukkan dasar negara berkonstitusi keislaman. Visi negara bangsa yang mengutamakan nilai keagamaan telah termaktub secara jelas pada dasar negara sebagai, yaitu sila Ketuhanan Yang Maha Esa sebagai sila pertama. Dengan dasar negara itu, bangsa Indonesia telah menganut paham ketuhanan yang berarti keagamaan, dimana nilai-nilai spiritualitas agama menjadi fondasi kehidupan berbangsa dan bernegara.

Ilmu dan metodologi keislaman juga dipadukan agar antara substansi keilmuan tidak terlepas dari akar metodologisnya, yaitu bahwa ilmu pengetahuan sebagai hasil pemikiran dan penelitian manusia selalu mempunyai keterbatasan, sehingga kajian metodologisnya akan selalu membuka peluang besar untuk pengembangan ilmu pengetahuan. Ilmuilmu keislaman sebagai basis kecerdasan spiritual juga tidak luput dari kajian metodologisnya agar selalu berkembang dan mampu menjawab tantangan zaman. Ilmu aqidah, ilmu syariah, ilmu akhlak sebagai basis ajaran agama Islam tidak boleh stagnan dalam satu titik yang jumud tetapi terus dikembangkan oleh para ulama dan para ahlinya sehingga menjadi ilmu yang layak untuk semua zaman dimana milyaran muslim di seluruh dunia harus hidup dengan dunia mereka masing-masing dengan berpegang teguh kepada spiritualitas beragama Islam.

Fiqh dengan sejarah peradaban Islam menjadi satu rumpun karena pada hakekatnya fiqh merupakan budaya manusia yang merespon terhadap al-Qur'an dan hadits dengan pemahaman dan ijtihad. Fiqh mempunyai sifat dasarnya sebagai hasil penafsiran, hasil berpendapat, dan hasil berintinbat melalui berbagai metode sehingga fiqh menjadi prosedur melaksanakan syariah. Perkembangan kajian dan produk fiqh dari masa ke masa juga untuk menjawab tantangan dan perkembangan zaman sehingga fiqh benarbenar menjadi perilaku berbudaya masyarakat muslim. Demikian pula sejarah perkembangan Islam dari zaman ke zaman, di berbagai wilayah yang berbeda-beda bisa menjadi khazanah sosial yang membuktikan bahwa Islam benar-benar menjadikan manusia berperadaban.

Praktik ibadah sebagai mata kuliah dengan kuliah kerja nyata (KKN) menjadi satu rumpun yang berarti bahwa nilai-nilai spiritual keagamaan menjadi titik sentral pengabdian kepada masyarakat. Dengan kata lain, 
pengabdian seorang sarjana pendidikan mempunyai bidang yang khusus, yaitu mengabdikan ilmu dan keterampilannya kepada masyarakat dalam pemberdayaan pendidikan dan nilai-nilai spiritual keagamaan. Fokus utama pengabdian kepada masyarakat adalah memberikan manfaat kepada masyarakat melalui aktifitas profesional maupun nonprofesional terutama di bidang pendidikan dan keagamaan. Sarjana pendidikan menjadi figur utama di masyarakat bahwa mereka mempunyai kemampuan untuk memberdayakan masyarakat secara baik sehingga kehidupan beragama di masyarakat semakin baik pula.

Materi perkuliahan bimbingan dan konseling, perkembangan anak, dan kesehatan mental dasar-dasar pembimbingan kepada peserta didik. Guru yang mementingkan kecerdasan spiritual peserta didiknya selalu mendasari bimbingan dan pengarahan kepada anak-anak dengan dasar nilai-nilai al-Quran dan hadits. Pembimbingan kepada peserta didik bukan hanya menjadikan mereka tumbuh dewasa secara fisik dan mental, tetapi juga sekaligus membimbing untuk dewasa secara spiritual keagamaan.

Sistem pembelajaran untuk beberapa mata kuliah tersebut dengan didasarkan pada penguasaan kompetensi, tujuan, indikator, strategi dan evaluasi pembelajaran. Kompetensi yang harus dicapai adalah kemampuan untuk memahami dan bersikap secara benar sebagai warga negara Indonesia yang berketuhanan Yang Maha Esa dan cinta tanah air dan bangsa. Pembelajarannya berorientasi konstruktivistik yang bertumpu pada keaktifan belajar mahasiswa melalui kegiatan diskusi, eksplorasi, komunikasi dengan berfikir kritis, analitis dan sintesis dibantu dengan pemanfaatan berbagai sumber belajar. Pelaksanaan perkuliahan dengan pendekatan yang digunakan lebih mengedepankan participatory dan andragogi. Pendekatan individual, kelompok, konsep dan proses, konstruktif, dan deduktif-induktif juga dipergunakan. Metode pembelajaran yang diterapkan adalah metode ceramah, simulasi, diskusi, demonstrasi, peer-teaching, dan praktik. Sedangkan model pembelajaran yang diterapkan antara lain small group discussion, simulasi, demonstrasi, praktik, discovery learning, self-directed learning, cooperative learning, collaborative learning, project based learning dan problem based learning. Berdasarkan dokumen naskah akademik kurikulum, model pembelajaran di STAIN Kudus digambarkan sebagai berikut : 
MODEL PEMBELAJARAN

\begin{tabular}{|c|c|c|c|}
\hline No & $\begin{array}{l}\text { Metode/ } \\
\text { Strategi }\end{array}$ & Peran Mahasiswa & Peran Dosen \\
\hline 1 & $\begin{array}{l}\text { Small Group } \\
\text { Discussion }\end{array}$ & $\begin{array}{l}\text { Membentuk kelompok } \\
\text { 5-10 orang, memilih bahan } \\
\text { diskusi, memperesentasikan } \\
\text { paper atau karya ilmiah dan } \\
\text { mendiskusikan di dalam } \\
\text { kelas }\end{array}$ & 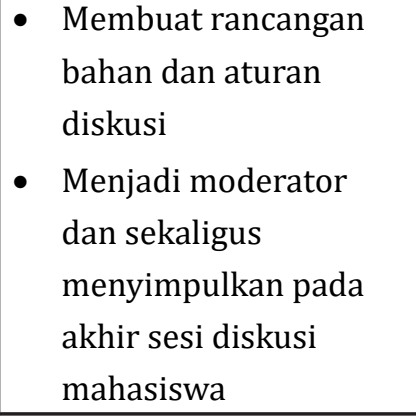 \\
\hline 2 & $\begin{array}{l}\text { Simulasi } \\
\text { dan/atau } \\
\text { demonstrasi }\end{array}$ & $\begin{array}{l}\text { Mempelajari dan } \\
\text { menjalankan suatu peran } \\
\text { yang ditugaskan atau } \\
\text { mempraktikkan/mencoba } \\
\text { berbagai model yang telah } \\
\text { disiapkan }\end{array}$ & $\begin{array}{l}\text { - Merancang situasi/ } \\
\text { kegiatan yang } \\
\text { mirip dengan yang } \\
\text { sesungguhnya, bisa } \\
\text { berupa bermain peran } \\
\text { atau berbagai latihan } \\
\text { simulasi lainnya }\end{array}$ \\
\hline 3 & $\begin{array}{l}\text { Discovery } \\
\text { Learning dan } \\
\text { self-directed } \\
\text { learning }\end{array}$ & $\begin{array}{l}\text { Mencari, mengumpulkan, } \\
\text { dan menyusun informasi } \\
\text { data yang ada untuk } \\
\text { mendeskripsi suatu } \\
\text { pengetahuan. Kemudian } \\
\text { merencanakan kegiatan } \\
\text { belajar, melaksnanakan, } \\
\text { dan menilai pengalaman } \\
\text { belajarnya sendiri }\end{array}$ & $\begin{array}{l}\text { - Menyediakan data atau } \\
\text { petunjuk atau metode } \\
\text { untuk menelusuri suatu } \\
\text { pengetahuan yang } \\
\text { harus dipelajari oleh } \\
\text { mahasiswa } \\
\text { - Memeriksa dan } \\
\text { memberi usulan } \\
\text { terhadap hasil belajar } \\
\text { mandiri mahasiswa } \\
\text { Sebagai fasilitator } \\
\text { memberi arahan, } \\
\text { bimbingan, dan } \\
\text { konfirmasi terhadap } \\
\text { kemajuan belajar } \\
\text { yang telah dilakukan } \\
\text { mahasiswa secara } \\
\text { individu }\end{array}$ \\
\hline
\end{tabular}




\begin{tabular}{|c|c|c|c|}
\hline 4 & $\begin{array}{l}\text { Cooperative } \\
\text { learning }\end{array}$ & $\begin{array}{l}\text { Membahas dan } \\
\text { menyimpulkan masalah/ } \\
\text { tugas yang diberikan dosen } \\
\text { secara berkelompok }\end{array}$ & $\begin{array}{l}\text { - Merancang dan } \\
\text { memonitor proses } \\
\text { belajar dan hasil belajar } \\
\text { kelompok mahasiswa } \\
\text { - Menyiapkan suatu } \\
\text { masalah/kasus lain } \\
\text { untuk diselesaikan } \\
\text { oleh mahasiswa secara } \\
\text { berkelompok }\end{array}$ \\
\hline 5 & $\begin{array}{l}\text { Collaborative } \\
\text { Learning }\end{array}$ & $\begin{array}{l}\text { Bekerjasama dengan } \\
\text { anggota kelompok dalam } \\
\text { mengerjakan tugas, membuat } \\
\text { rancangan proses dan bentuk } \\
\text { penilaian berdasarkan } \\
\text { konsensus kelompoknya } \\
\text { sendiri }\end{array}$ & $\begin{array}{l}\text { - Merancang tugas yang } \\
\text { sifatnya open minded } \\
\text { - Sebagai inspirator, } \\
\text { fasilitator dan motivator } \\
\text { pembelajaran }\end{array}$ \\
\hline 6 & $\begin{array}{l}\text { Project based } \\
\text { learning dan } \\
\text { problem } \\
\text { based } \\
\text { learning }\end{array}$ & $\begin{array}{l}\text { Mengerjakan tugas, } \\
\text { berupa proyek yang telah } \\
\text { dirancang secara sistematis. } \\
\text { Menunjukkan kinerja dan } \\
\text { mempertanggungjawabkan } \\
\text { hasil kerjanya di forum. } \\
\text { Belajar dengan menggali } \\
\text { atau mencari informasi/ } \\
\text { inquiri melalui pemanfaatan } \\
\text { informasi guna memcahkan } \\
\text { masalah faktual yang } \\
\text { dirancang oleh dosen }\end{array}$ & $\begin{array}{l}\text { - Merancang suatu tugas } \\
\text { proyek yang sistematis } \\
\text { agar mahasiswa belajar } \\
\text { pengetahuan dan } \\
\text { keterampilan melalui } \\
\text { proses pencarian/ } \\
\text { penggalian informasi } \\
\text { - Menemukan dan } \\
\text { melakukan proses } \\
\text { pembimbingan dan } \\
\text { asesmen } \\
\text { Merancang tugas untuk } \\
\text { mencapai kompetensi } \\
\text { tertentu } \\
\text { Membuat petunjuk } \\
\text { untuk mahasiswa dalam } \\
\text { mencari pemecahan } \\
\text { masalah yang dipilih } \\
\text { oleh mahasiswa sendiri } \\
\text { atau yang ditetapkan }\end{array}$ \\
\hline
\end{tabular}


Berdasarkan dokumen kurikulum dan observasi lapangan, proses pembelajaran didukung oleh media pembelajaran berbasis teknologi informasi dan komunikasi, laboratorium pembelajaran, laboratorium ibadah, laboratorium bahasa, dan kuliah lapangan di mana masyarakat menjadi laboratorium kerja lapangan. Selain itu dosen dan pengelola merancang dan menyusun instrumen dan perangkat perkuliahan, diantaranya silabus, rencana pembelajaran semester, kontrak perkulihan dan bahan ajar di awal perkuliahan.

Sistem evaluasi atau penilaian menggunakan standar yang tertuang dalam kurikulum pendidikan tinggi berbasis kerangka kualifikasi nasional Indonesia (KKNI) yang mengacu pada Standar Nasional Pendidikan Tinggi (SNPT) bahwa penilaian proses dan hasil belajar mahasiswa dalam rangka pemenuhaan capaian pembelajaran lulusan, penilaian proses dan hasil belajar mahasiswa mencakup: (1) prinsip penilaian, (2) teknik dan instrumen penilaian, (3) mekanisme dan prosedur penilaian; (4) pelaksanaan penilaian, (5) pelaporan penilaian, dan (6) kelulusan mahasiswa. Dalam pelaksanaannya, penilaian menganut prinsip-prinsip edukatif, otentik, objektif, akuntabel dan transparan yang dilakukan secara terintegrasi.

\section{Simpulan}

Pendidikan bagi calon guru yang akan mengajar di pendidikan anak usia dini merupakan pendidikan khusus yang mengandalkan nilai-nilai kepribadian dan spiritual agama Islam, karena itu maka kurikulum dan pembelajarannya juga memastikan bahwa kecerdasan spiritual itu bagian terpenting dalam program pendidikan calon guru. Bukti bahwa nilai-nilai spiritual keagamaan itu mendasari pendidikan calon guru terlihat jelas pada terstrukturnya rumpun mata kuliah keagamaan yang terintegrasi dengan materi lainnya. Pendidikan teologi bersanding dengan pendidikan kebangsaan, pendidikan dasar-dasar keislaman bersanding dengan kajian metodologisnya, pendidikan kesehatan mental bersanding dengan kajian alQuran dan hadits sebagai spiritnya, dan praktikum keagamaan bersanding dengan kuliah nyata berkehidupan bermasyarakat. Pendidikan kecerdasan spiritual telah menjadi dasar utama pendidikan calon guru yang akan mengajar di jenjang pendidikan anak usia dini. 


\section{DAFTAR PUSTAKA}

McMillan, James H and Sally Schumacher. 2001. Research In Education A Conceptual Introduction. San Francisco: Longman.

Moleong, Lexy J. 2000. Metodologi Penelitian Kualitatif. Yogyakarta: Rake Sarasin.

Newman, Joseph W. 1994. America's Teachers An Introduction to Education. New York:Longman.

Tim. 2016. Naskah Akademik Kurikulum PGRA STAIN Kudus. Kudus:STAIN Kudus.

Ali, As'ad Said. 2010. Negara Pancasila Jalan Kemaslahatan Berbangsa. Jakarta:LP3ES.

Undang-Undang Republik Indonesia Nomor 12 tahun 2012 tentang Pendidikan Tinggi.

Undang-Undang Republik Indonesia Nomor 14 tahun 2005 tentang Guru dan Dosen.

Undang-Undang Republik Indonesia Nomor 20 Tahun 2003 tentang Sistem Pendidikan Nasional. Jakarta:Dihimpun oleh Penerbit Asa Mandiri. 